\title{
Co-relation of Myopia with the Use of Smart Phones and Outdoor Activities
}

\author{
Hafiza Sadia Imtiaz ${ }^{1}$, Muhammad Sharjeel ${ }^{2}$, Irfan Qayyum Malik ${ }^{3}$ \\ Department of Ophthalmology, ${ }^{1,3}$ Gujranwala Medical College, Gujranwala \\ ${ }^{2}$ Gomal Medical College, Dera Ismail Khan
}

\begin{abstract}
Purpose: To determine the frequency of myopia among children and to find out the role of smart phone usage and outdoor activities in myopia development and progression.
\end{abstract}

Study Design: Descriptive cross-sectional study.

Place and Duration of Study: Ophthalmology Department DHQ-UTH Gujranwala, from January 2019 to June 2019.

Methods: After approval from the hospital ethical committee and informed consent from each participant, a descriptive cross-sectional study was carried out with a sample size of 250 patients. Patients of either gender between $4-14$ years of age using smart phones for $\geq 2$ hours daily and found to have refractive error were included in this study. Routine ophthalmic examination was carried out, data was recorded on proforma, and daily usage of smart phones and weekly outdoor activity in hours along with school grade, family history and previous history of using refractive glasses was also determined and documented. Data was analyzed using SPSS v.20

Results: There were 250 patients included in this study, out of which 142 (56.8\%) were male and 108 (43.2\%) were female. Mean age was $10.1 \pm 2.45$ years. Mean outdoor activity was $0.95 \pm 0.98$ hours per week while mean daily smart phone usage was $2.89 \pm 0.93$ hours. Pearson correlation coefficient for daily smart phone usage and UCVA was $+0.297(0.3)$ which showed a positive moderate association between two variables while the value obtained for UCVA and weekly outdoor activity was -0.51 that depicted a negative strong association.

Conclusions: In conclusion, myopia occurrence is higher among smart phone users showing a moderate positive correlation while outdoor activities reduce myopia prevalence and progression depicting strong negative correlation.

Key Words: Refractive Errors, Myopia, Visual acuity, Smartphone.

How to Cite this Article: Imtiaz HS, Sharjeel M, Malik IQ. Association of Myopia with the Use of Smart Phones and Outdoor Activities in Pakistan. Pak J Ophthalmol. 2020; 36 (4): 376-380.

Doi: https://doi.org/10.36351/pjo.v36i4.1067

\section{INTRODUCTION}

Myopia is the commonest refractive error. Its prevalence varies considerably over various regions of

Correspondence: Hafiza Sadia Imtiaz

Department of Ophthalmology

Gujranwala Medical College, Gujranwala

Email: sadiaimtiaz69@gmail.com

Received: May 18, 2020

Accepted: July 31, 2020 the world with the maximum growing tendency among East Asian countries. ${ }^{1}$ It can occur in adults and children and its worldwide prevalence is $30 \% .^{2}$ According to some recent studies, number of people who developed myopia were about 1406 million in 2000 which increased to 1950 million in 2010 and it is highly predicted that this number will increase to 4758 million by $2050 .^{3}$

Etiology of myopia is quite cumbersome with complex interactions between genetic and environmental factors. Many researchers have studied 
various genes involved with onset and progression of myopia which include IGF-1, PAX-6 gene, and BicC family RNA binding protein $1 .^{4,5,6}$ Previously, it was assumed that only genetic factors contribute towards myopia but newer researches have documented the strong association of environmental factors. For example, high intelligence and education, lifestyle, low vitamin D levels, and most importantly use of electronic devices including the smartphones. ${ }^{7,8}$

Computers, tablets, and smart phones are the demand of every home and working environment and are considered to be a part and parcel of modern life. Children are among the most growing users of smart phones and that is reflected by the international statistics. Many studies have linked myopia progression with the use of smart phones due to small screens and close working distance. Close target results in retinal defocusing which causes the eye to accommodate thus increasing its power to bring near objects in sharp focus. Areas of defocus on retina render the eyeball to grow thus adding to the magnitude of myopia. ${ }^{9}$

The purpose of this study is to determine the prevalence of myopia among children and also to find out the role of smart phone usage as a contributing factor to myopia development and progression.

\section{METHODS}

After approval from the hospital ethical committee, verbal informed consent was collected from each patient/guardian. Patients of either gender between 414 years of age using smart phones for $\geq 2$ hours daily presented to eye outdoor patient department of DHQUTH Gujranwala. Patients with any other intraocular disease or previous history of intraocular surgery were excluded from this study. It was a descriptive crosssectional study with a sample size of 250 patients (included by convenient sampling technique) and time duration of six months (January - June 2019).

All included patients underwent the routine ophthalmic examination of visual acuity with pinhole testing, refractive error evaluation with the use of autorefractometer followed by subjective refraction to determine the best-corrected visual acuity (BCVA). Slit-lamp biomicroscopy and fundoscopy were carried out to exclude other causes of reduced visual acuity. Data was collected on a self-designed Performa. Daily usage of smart phones and weekly outdoor activity in hours along with school grade, family history and previous history of using refractive glasses was also determined and documented.

Data was analyzed using SPSS version 20. Frequencies and percentages were calculated for categorical variables like gender, school grade, family history, previous history of using refractive glasses and age groups while Mean \pm S.D was computed for numerical variables like age, visual acuity (log MAR) and refractive error (Diopters). Pearson's correlation was used to determine the significant association as well as strength of association between Visual acuity (log MAR) and time spent using a smart phone and in outdoor activities with r-value denoting the strength of association and $r$-sign showing a positive or negative association.

\section{RESULTS}

250 patients were included in this study, out of whom $142(56.8 \%)$ were male and $108(43.2 \%)$ were female. Mean age was $10.1 \pm 2.45$ years and all patients were divided into three age groups with 41 patients (16.4\%) in $4-7$ years age group, $105(42 \%)$ in $8-11$ years age group and $104(41.6 \%)$ in $12-14$ years age group.

Patients were also stratified according to school grade into three groups of $0-4$ class, $5-8$ class, $9-$ 12 class, and their frequency as well as percentage in each group is depicted via the following pie chart; (Figure 1).

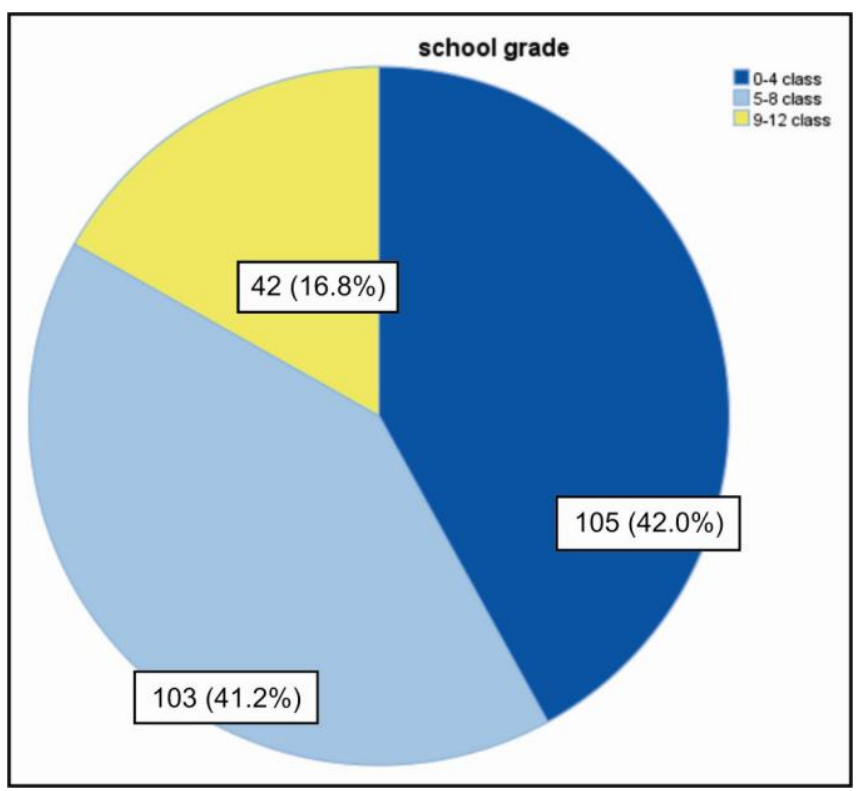

Fig. 1: Pie chart showing stratification according to school grade. 
Family history of Myopia was present among $40.4 \%$ of patients and the previous history of using glasses was present only in $17.6 \%$ of patients.

Mean outdoor activity recorded was $0.95 \pm 0.98$ hours per week. Thirty eight percent patients had no outdoor activity, $28.4 \%$ had 1 hour and $22 \%$ had 2 hours of weekly outdoor activity. Mean daily smart phone usage was $2.89 \pm 0.93$ hours. $38.4 \%$ with 2 hours daily usage, $8.0 \%$ with 2.5 hours, $29.2 \%$ with 3 hours, $0.4 \%$ with 3.5 hours, $17.6 \%$ with 4 hours, $5.6 \%$ with 5 hours and $0.8 \%$ with 6 hours daily smart phone usage shown by bar chart in figure 2 .

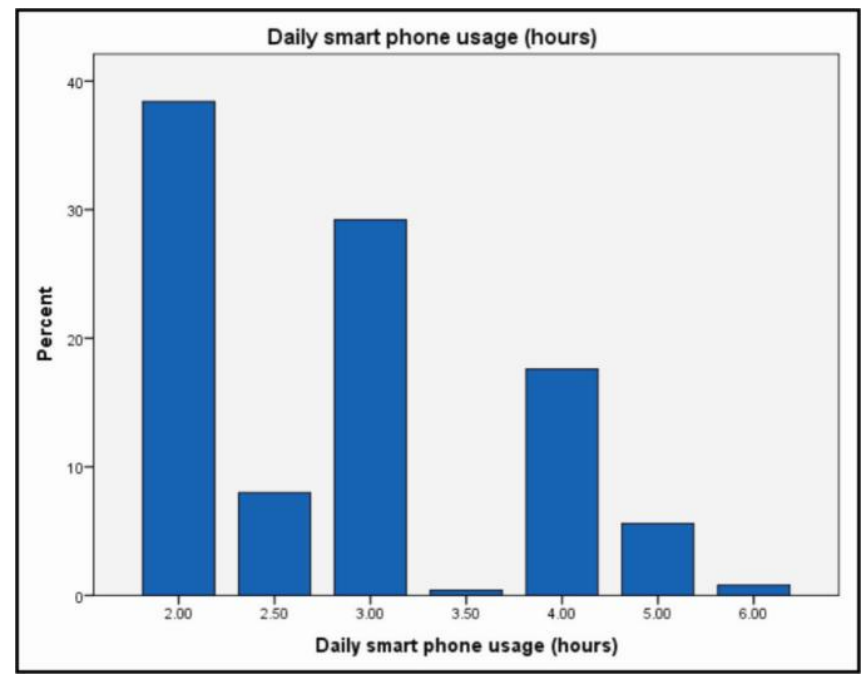

Fig. 2: Bar Chart Showing Daily Smart Phone Usage in Hours.

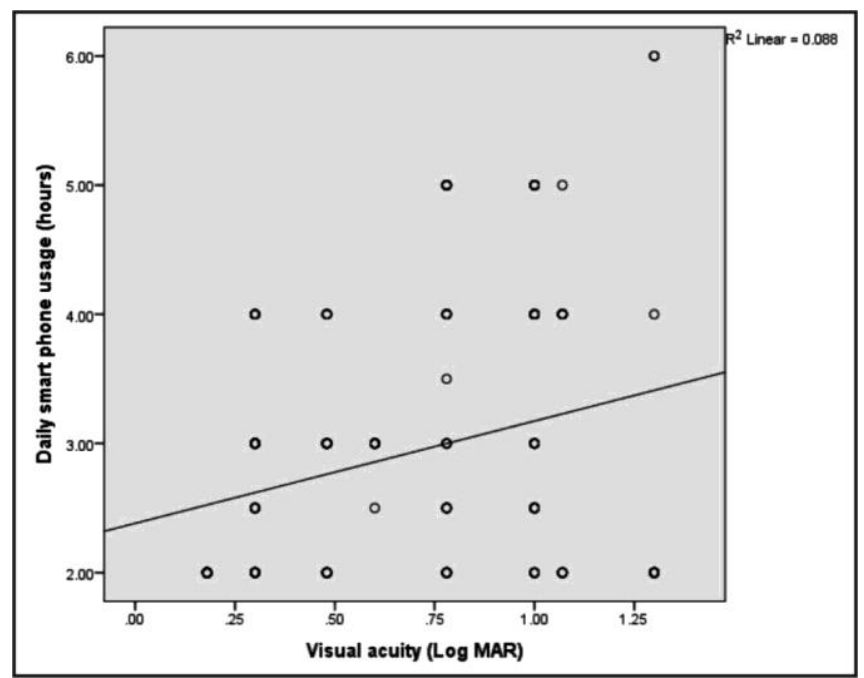

Fig. 3: Scatter Chart Showing Positive Correlation between Daily Smart Phone Usage and UCVA (Log MAR).
Mean uncorrected visual acuity (UCVA) was log MAR $0.64 \pm 0.35$ and the range was $\log$ MAR $0.18-$ 1.30. Mean refractive error was $-1.31 \pm 1.64 \mathrm{D}$ with $92 \%$ having myopia while $8 \%$ with hyperopic refractive error. Following is the simple scatter graph between UCVA (log MAR) and daily smart phone usage (hours) and it shows $\mathrm{R}^{2}$ linear of 0.088 and a positive association between two variables (Figure 3).

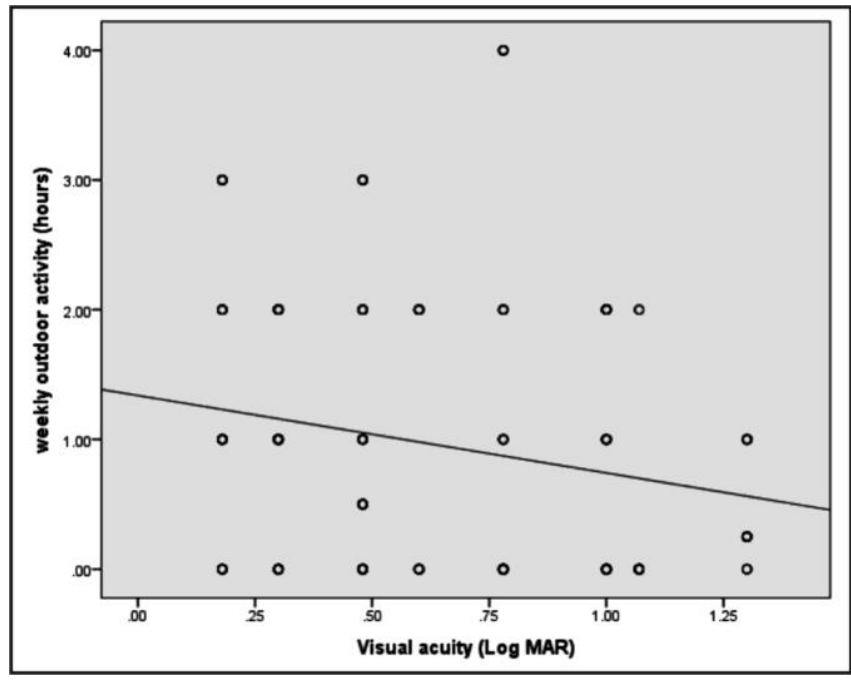

Fig. 4: Scatter chart showing -ve correlation $b / w$ weekly outdoor activity and UCVA (Log MAR).

Assuming linear relationship between smart phone usage and UCVA (log MAR), Pearson correlation coefficient obtained was $0.297(0.3)$ that shows intermediate/moderate association between two variables and positive direction of relationship depicts that increased smart phone usage causes increased UCVA (refractive error) (Table 1).

Following is the simple scatter graph between UCVA (log MAR) and weekly outdoor activity (hours) and it shows $\mathrm{R}^{2}$ linear of 0.2601 and negative correlation (Figure 4).

Table 1: Correlations b/w smart Phone Usage and UCVA.

\begin{tabular}{llcc}
\hline & & $\begin{array}{c}\text { Daily Smart } \\
\text { Phone Usage } \\
\text { (Hours) }\end{array}$ & $\begin{array}{c}\text { Uncorrected } \\
\text { Visual Acuity } \\
\text { (Log Mar) }\end{array}$ \\
\hline $\begin{array}{l}\text { Daily smart } \\
\text { phone usage } \\
\text { (hours) }\end{array}$ & $\begin{array}{l}\text { Pearson Correlation } \\
\text { Sig. (2-tailed) }\end{array}$ & 1 & $.297^{* *}$ \\
UCVA & Pearson Correlation & 250 & .000 \\
(Log MAR) & Sig. (2-tailed) & $.297^{* *}$ & 250 \\
& $\mathrm{~N}$ & .000 & 1 \\
\hline
\end{tabular}

**. Correlation is significant at the 0.01 level (2-tailed). 
Pearson correlation coefficient test was applied to determine the association between UCVA and weekly outdoor activity and it showed strong association ( $\mathrm{r}=$ $0.51)$. Negative sign depicts direction of association and thus increased outdoor activity is associated with less UCVA (refractive error) (Table 2).

Table 2: Correlation b/w UCVA and Outdoor Activity.

\begin{tabular}{llcc}
\hline & & $\begin{array}{l}\text { Visual Acuity } \\
\text { (Log MAR) }\end{array}$ & $\begin{array}{l}\text { weekly Outdoor } \\
\text { Activity (Hours) }\end{array}$ \\
\hline UCVA & Pearson & 1 & $-.510^{* * *}$ \\
(Log MAR) & Correlation & & .001 \\
& Sig. (2-tailed) & & 250 \\
& N & 250 & 1 \\
weekly outdoor & Pearson & $-.510^{* *}$ & \\
activity (hours) & Sig. (2-tailed) & .001 & 250 \\
& $\mathrm{~N}$ & 250 & 250 \\
\hline
\end{tabular}

**. Correlation is significant at the 0.01 level (2-tailed).

\section{DISCUSSION}

Myopia is a growing problem in the field of ophthalmology and here comes the need to determine its aggravating factors. In this study, we determined the relationship between smart phone usage and outdoor activity with myopia. Results showed the male to female ratio of $1.3: 1$ with a mean age of 10 years. Hittalamani et al. determined myopia prevalence among school-going children and their results showed that it was more common among girls 155 (58.27\%) than boys $111(41.73 \%){ }^{10}$

Family history was present in $40.4 \%$ of patients in our study showing a remarkable genetic association and it was more marked in children with high refractive error of $>5.00 \mathrm{D}$. This finding is supported by another study carried out in Taiwan which showed an Odd's Ratio of $>5.5$ among high myopic patients with positive family history depicting a strong association. ${ }^{11}$ Iribarren et al. modified this approach and proved with their study that family history though important but not related to the final amount of refractive error in low and moderate myopia. ${ }^{12}$

Mean outdoor activity recorded in our study is almost 1 hour per week and Pearson correlation showed a strong negative correlation $(\mathrm{r}=-0.51)$ between outdoor activities and reduced visual acuity (refractive error). This finding is supported by many ongoing researches which showed a positive impact of outdoor activities in slowing the development and progression of myopia. ${ }^{13}$ Oner et al. showed that myopia progression was associated with time spent on reading and writing and initial refraction value, during puberty. ${ }^{14}$ Several hypotheses are presented to focus on different aspects of outdoor activity, to explain the role of more outdoor activity in protecting against myopia. One is that the constricted pupil under sunlight leads to increased depth of focus and decreased blurriness. Another hypothesis is elevated retinal dopamine activity with sunlight exposure. This results in exposure to different light spectrums in natural light as compared to indoor light. Far less diopter variation in outdoor activities is also considered a contributing factor. ${ }^{15}$ A meta-analysis was carried out by Deng L and Pang Y and results suggested a lower risk of myopia onset and myopic shift with more time spent in outdoor activities. ${ }^{16}$

Mean daily smart phone usage recorded in this study was $2.89 \pm 0.93$ hours. Pearsons correlation coefficient depicted an intermediate/moderate positive association $(\mathrm{r}=+0.297)$ between daily smart phone usage and refractive error. Previous data is lacking in documenting an association between smart phone usage and myopia development though studies are available regarding the use of electronic devices ${ }^{17}$ and near work.

A cross-sectional survey was carried out in Beijing in 2008. The data was collected from 15,316 Chinese school students aged 6 to 18 years. Univariate and multiple logistic regression analyses were performed to compare the differences among different areas. Myopia was associated with shorter sleep times versus longer sleep times. It was also related with reading or writing distances less than $33 \mathrm{~cm}$ compared to distances greater than $33 \mathrm{~cm} .{ }^{18}$ Other studies showed association of near work with increase in myopia. ${ }^{19,20}$

The limitation of this study is that it is a crosssectional study where further follow up of patients was not done. Future studies will be carried out for a longer follow-up to determine the effect of smart phone usage upon the progression of myopia.

\section{CONCLUSION}

In conclusion, myopia occurrence is higher among smart phone users showing a moderate positive correlation while outdoor activities reduce myopia prevalence and progression depicting a strong negative correlation. 


\section{Ethical Approval}

The study was approved by the Institutional review board/Ethical review board.

\section{Conflict of Interest}

Authors declared no conflict of interest.

\section{REFERENCES}

1. Ding B, Shih Y, Lin L, Hsiao C, Wang I. Myopia among school children in East Asia and Singapore. Surv Ophthalmol. 2017; 62 (5): 677-697.

2. R. Greene $\mathbf{P}, \mathbf{M}$. Green J. Prevalence and incidence of myopia and high myopia. New Front Ophthalmol. 2016; 2 (6): 1-4.

3. Holden B, Fricke T, Wilson D, Jong M, Naidoo K, Sankaridurg P et al. Global Prevalence of Myopia and High Myopia and Temporal Trends from 2000 through 2050. Ophthalmol. 2016; 123 (5): 1036-1042.

4. Guo L, Du X, Lu C, Zhang W. Association between Insulin-Like Growth Factor 1 Gene rs12423791 or rs6214 Polymorphisms and High Myopia: A MetaAnalysis. PLoS One. 2015; 10 (6): 1-14.

5. Tang $\mathbf{S}$, Rong $\mathbf{S}$, Young $A$, Tam $P$, Pang $\mathbf{C}$, Chen $\mathbf{L}$. PAX6 Gene Associated with High Myopia. Optom Vis Sci. 2014; 91 (4): 419-429.

6. Jin W, Hepei L, Mingkun X, Li W. Assessment of BicC family RNA binding protein 1 and Ras protein specific guanine nucleotide releasing factor 1 as candidate genes for high myopia: A case-control study. Indian J Ophthalmol. 2017; 65 (10): 926-930.

7. Verma A, Verma A. A Novel Review of the Evidence Linking Myopia and High Intelligence. J Ophthalmol. 2015; 2015 (2015): 1-8.

8. Yazar S, Hewitt A, Black L, McKnight C, Mountain J, Sherwin J et al. Myopia Is Associated With Lower Vitamin D Status in Young Adults. Invest Ophthalmol Vis Sci. 2014; 55 (7): 4552-4559.

9. Lougheed T. Myopia: The Evidence for Environmental Factors. Environ Health Perspect. 2014; 122 (1): A1319.

10. Hittalamani S, Jivangi V. Prevalence of myopia among school going children. Int J Res Med Sci. 2015; 3 (10): 2786-2790.

11. Liang C, Yen E, Su J, Liu C, Chang T, Park $\mathbf{N}$ et al. Impact of Family History of High Myopia on Level and Onset of Myopia. Invest Ophthalmol Vis Sci. 2004; 45 (10): 3446 .
12. Iribarren R, Balsa A, Armesto A, Chiaradia P, Despontin L, Fornaciari A et al. Family history of myopia is not related to the final amount of refractive error in low and moderate myopia. Clin Exp Ophthalmol. 2005; 33 (3): 274-278.

13. Suryathi N, Budhiastra I, Handayani A. Outdoor Activities and Myopia on Junior High School Student in Rural Area of Bali. Ophthalmologica Indonesiana. 2018; 44 (1): 30.

14. Öner V, Bulut A, Oruç Y, Özgür G. Influence of indoor and outdoor activities on progression of myopia during puberty. Int Ophthalmol. 2015; 36 (1): 121-125.

15. Deng L, Pang Y. The role of outdoor activity in myopia prevention. J Eye Sci. 2015; 30 (4): 137-139.

16. Deng L, Pang Y. Effect of Outdoor Activities in Myopia Control. Optom Vis Sci. 2019; 96 (4): 276-282.

17. Liu S, Ye S, Xi W, Zhang X. Electronic devices and myopic refraction among children aged 6-14 years in urban areas of Tianjin, China. Ophthalmic Physiol Opt. 2019; 39 (4): 282-293.

18. Gong Y, Zhang X, Tian D, Wang D, Xiao G. Parental myopia, near work, hours of sleep and myopia in Chinese children. Health, 2014; 06 (01): 64-70.

19. Sivaraman V, Rizwana J, Ramani K, Price H, Calver R, Pardhan $\mathbf{S}$ et al. Near work-induced transient myopia in Indian subjects. Clin Exp Optom. 2015; 98 (6): 541-546.

20. Muhamedagic L, Muhamedagic B, Halilovic E, Halimic J, Stankovic A, Muracevic B. Relation Between Near Work and Myopia Progression in Student Population. Mater Sociomed. 2014; 26 (2): 100 .

\section{Authors' Designation and Contribution}

Hafiza Sadia Imtiaz; Postgraduate Trainee: Manuscript writing, Data collection, Data Analysis.

Muhammad Sharjeel; Senior Registrar: Topic Selection, Data collection, Data Analysis.

Irfan Qayyum Malik; Associate Professor: Supervisor, Study design, Manuscript review. 